\title{
A ESTAÇÃO PALEOLÍTICA DA PRAIA DA AGUDA (ARCOZELO, VILA NOVA DE GAIA). NOTÍCIA PRELIMINAR
}

\author{
SÉrgio Monteiro-Rodrigues(1) \& ANTÓNio GONZÁleZ(2)
}

Resumo

Abstract

\section{INTRODUÇÃo}

No litoral do Porto e de Vila Nova de Gaia, a existência de indústrias líticas técnica e tipologicamente conectáveis com a Pré-história Antiga é conhecida pelo menos desde os finais do século XIX, altura em que Frederico de Vasconcellos Pereira Cabral publicou os seus estudos sobre os depósitos sedimentares da Bacia do Douro. Desde então, e até aos meados do século XX, autores como Joaquim Fontes, Rui de Serpa Pinto, Fernando Russell Cortez, Georges chronology.

\begin{abstract}
A existência de materiais líticos paleolíticos no litoral do Porto e de Vila Nova de Gaia é conhecida, pelo menos, desde os finais do século XIX. A partir de 1987, trabalhos de prospeç̧ão neste último concelho conduziram à descoberta do sítio do Cerro (freguesia da Madalena), escavado em 1989 e em 1992. Tais escavações permitiram a recolha de uma indústria técnica e tipologicamente conectável com o Acheulense. A estação paleolítica da Praia da Aguda (Arcozelo, Vila Nova de Gaia), agora apresentada, foi, por seu turno, identificada em 2004. Pouco depois da sua descoberta recolheram-se mais de uma centena de artefactos macrolíticos conectáveis com o Paleolítico Inferior (bifaces, machados de mão, núcleos, utensílios sobre lasca, etc.). Inicialmente, estes artefactos foram correlacionados com um depósito marinho, possivelmente de idade eemiana, existente na área dos achados. Porém, trabalhos de campo subsequentes permitiram constatar que essa correlação não é segura uma vez que os artefactos líticos detectados in situ surgem num depósito com caraterísticas diferentes das observadas na formação atribuída à última interglaciação. Na impossibilidade, até ao momento, de se proceder a uma caraterização sedimentológica do depósito onde ocorrem os artefactos e de se estabelecer qualquer correlação estratigráfica entre este e a praia fóssil do Eemiano, equacionam-se algumas hipóteses relativamente à génese do sítio arqueológico e à sua cronologia relativa.
\end{abstract}

Palavras-chave: Paleolítico Inferior; Plataforma Litoral; Eemiano; Vila Nova de Gaia.

The existence of Palaeolithic stone tools on the coast of Porto and Vila Nova de Gaia has been known from at least the late nineteenth century. In 1987, survey investigations in the latter municipality led to the discovery of the site of Cerro (Madalena), excavated in 1989 and 1992. These excavations produced a collection of lithics that are techno-typologically related to the Acheulian. The Palaeolithic site of Praia da Aguda (Arcozelo), now published for the first time, was identified in 2004. Shortly after its discovery, more than one hundred macrolithic artefacts were found. The presence of hand-axes and cleavers suggests a Lower Palaeolithic chronology. Initially, these artefacts were associated with a marine deposit, possibly of Eemian age, which was outcropping in the area of the site. However, subsequent fieldwork showed that this correlation is not clear since the lithic artefacts that were found in situ were collected another deposit with features that differ from those observed in the Eemian deposit. So far it has to establish any stratigraphic correlation between this deposit and the Eemian fossil beach. Therefore,

Key-words: Lower Palaeolithic; Eemian; Vila Nova de Gaia; Littoral platform.

\footnotetext{
(1) Departamento de Ciências e Técnicas do Património - Faculdade de Letras da Universidade do Porto, Via Panorâmica, s/n, 4150 Porto, Portugal. Centro de Estudos Arqueológicos das Universidades de Coimbra e Porto (CEAUCP). sergiomonteirorodrigues@gmail.com (2) Arqueólogo. ARCA (Associação de Arqueologia da Amadora).
} 
materiais líticos da região, bem como melhor aferir as respectivas condições de jazida por forma a tentar estabelecer o seu correcto balizamento cronológico-cultural.

Entre os diversos achados então realizados (algumas centenas de artefactos, em muitos casos associados a contextos geológicos precisos), desde logo se destacou, em 1988, a descoberta do sítio do Cerro, na freguesia da Madalena (MONTEIRO-RodRIGUES \& CUNHA-RIBEIRO 1991; MONTEIRO-RODRIGUES \& SANCHES 2006). Neste local identificaram-se várias dezenas de objectos líticos talhados, associados a uma pequena cascalheira que havia sido parcialmente seccionada pela abertura de um estradão (idem). Tal concentração de material lítico impôs a realização de escavações arqueológicas ${ }^{1}$, algumas das quais levadas a efeito em contexto de emergência, uma vez que estava prevista a construção de um parque de campismo que afectaria parte da estação (MONTEIRO-Rodrigues \& CUNHA-Ribeiro 1991).

Muito embora não tenha sido ainda alvo de estudo detalhado, a indústria lítica recolhida no Cerro parece relacionar-se com o tecno-complexo Acheulense em função da presença significativa de bifaces. O seu contexto estratigráfico permite corroborar esta hipótese: o material lítico surge num depósito coluvionar que se sobrepõe a um depósito marinho cuja base se implanta a cerca de $25 \mathrm{~m}$ a.n.m. (MONTEIRO-RODRIGUES \& CUNHA-RIBEIRO 1991; MONTEIRO-RODRIGUES \& SANCHES 2006; ARAÚJO 1991).

A estação do Cerro, bem como a que agora se apresenta, constituem-se como duas estações arqueológicas de referência para o estudo do Paleolítico Inferior do Norte de Portugal.

\section{O Sítio Paleolítico da Praia da Aguda}

\subsection{A descoberta}

No Verão de 2004, António González recolheu em plena praia da Aguda, entre a Estação Litoral da Aguda (ELA) e as Piscinas da Granja, diversos artefactos líticos talhados. Alguns destes artefactos foram provisoriamente depositados na ELA, ficando ao cuidado do seu director, Mike Weber ${ }^{2}$.

Posteriormente, António González contactou Sérgio Monteiro-Rodrigues no sentido de se proceder à caracterização dos achados e a uma tentativa de delimitação da respectiva área de proveniência. Realizou-se, assim, em Janeiro de 2005, uma primeira deslocação ao terreno ${ }^{3}$, que permitiu constatar que os materiais líticos tendiam a concentrar-se numa área ligeiramente deprimida da plataforma de abrasão actual, apenas visível durante a maré baixa, coincidente com a zona de rebentação na preia-mar. Nessa mesma área observaram-se afloramentos residuais de uma praia fóssil (entretanto destruída pela erosão marinha), assentes no substrato de rochas metamórficas, pelo que se considerou que a presença dos materais talhados no local deveria resultar, precisamente, do desmantelamento da referida praia.

Uma vez que a plataforma litoral de Vila Nova de Gaia tem sido desde há vários anos objecto de inúmeros estudos de pormenor levados a cabo pela Professora M. Assunção Araújo, do Departamento de Geografia da Faculdade de Letras da Universidade do Porto (p.e. ARAÚJO 1991, 1995, 2000, 2004; ARAÚJO et al. 2003), optou-se, pouco depois da descoberta do sítio arqueológico, por contactar a referida investigadora com o objectivo de obter mais informações sobre aquele depósito marinho. Foi então referido, entre outros aspectos, que se trataria possivelmente de um depósito trangressivo do Eemiano (datado de cerca de $130.000 \mathrm{BP}$ a cerca de $115.000 \mathrm{BP}$, segundo os dados obtidos nas calotes de gelo da Gronelândia). Tendo em conta as características genéricas da indústria lítica identificada, tal atribuição cronológica pareceu perfeitamente adequada.

$\mathrm{Na}$ sequência dos referidos contactos, foi apresentada, em Setembro de 2005, uma comunicação na Sixth International Conference on Geomorphology (Saragoça), intitulada Eemien and Flandrian deposits on Porto (northern Portugal) littoral platform: the contribution of archaeology (ARAÚJO et al. 2005).

Actualmente, Sérgio Monteiro-Rodrigues continua a visitar a estação da Aguda com regularidade, procedendo, sempre que possível, à recolha de material lítico e à elaboração de diversos registos. Estas acções, aliás, suscitaram recentemente algumas questões relacionadas com o contexto estratigráfico do material talhado, que serão discutidas adiante.

\subsection{Localização geográfica}

A estação paleolítica localiza-se em plena praia da Aguda, $300 \mathrm{~m}$ a norte das Piscinas da Granja (Figs. 1 e 2). As coordenadas geográficas da área de

\footnotetext{
Os trabalhos de escavação foram coordenados por João Pedro Cunha-Ribeiro e Sérgio Monteiro-Rodrigues, e decorreram em Julho e finais de Outubro de 1989 e em Julho de 1992.

Algumas peças líticas ficaram, desde a sua descoberta, expostas no Museu das Pescas da ELA.

3 Mike Weber, que participou nesta saída de campo, publicou num livro da sua autoria (Weber, 2005) uma primeira nota sobre a descoberta da estação arqueológica.
} 


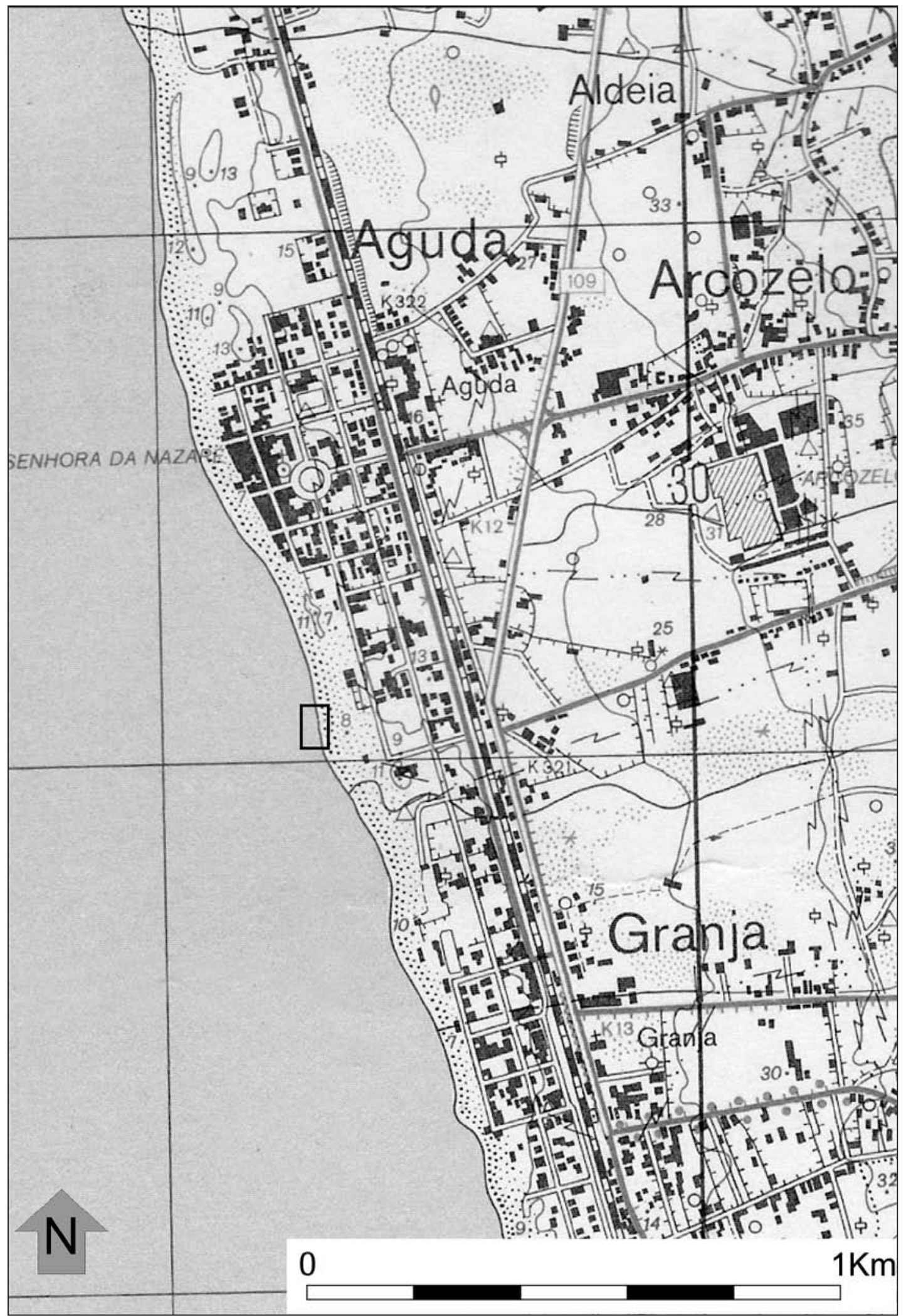

Fig. 1. Localização da estação paleolítica da Praia da Aguda (rectângulo negro) na Carta Militar de Portugal, folha 133 (Valadares, Vila Nova de Gaia), na escala 1:25000 (Instituto Geográfico do Exército, 1978). Modificada.

Fig. 1. Location of the Palaeolithic site of Praia da Aguda (black rectangle) in the Carta Militar de Portugal, chart 133 (Valadares, Vila Nova de Gaia), scale 1:25,000 (Instituto Geográfico do Exército, 1978). Modified. 


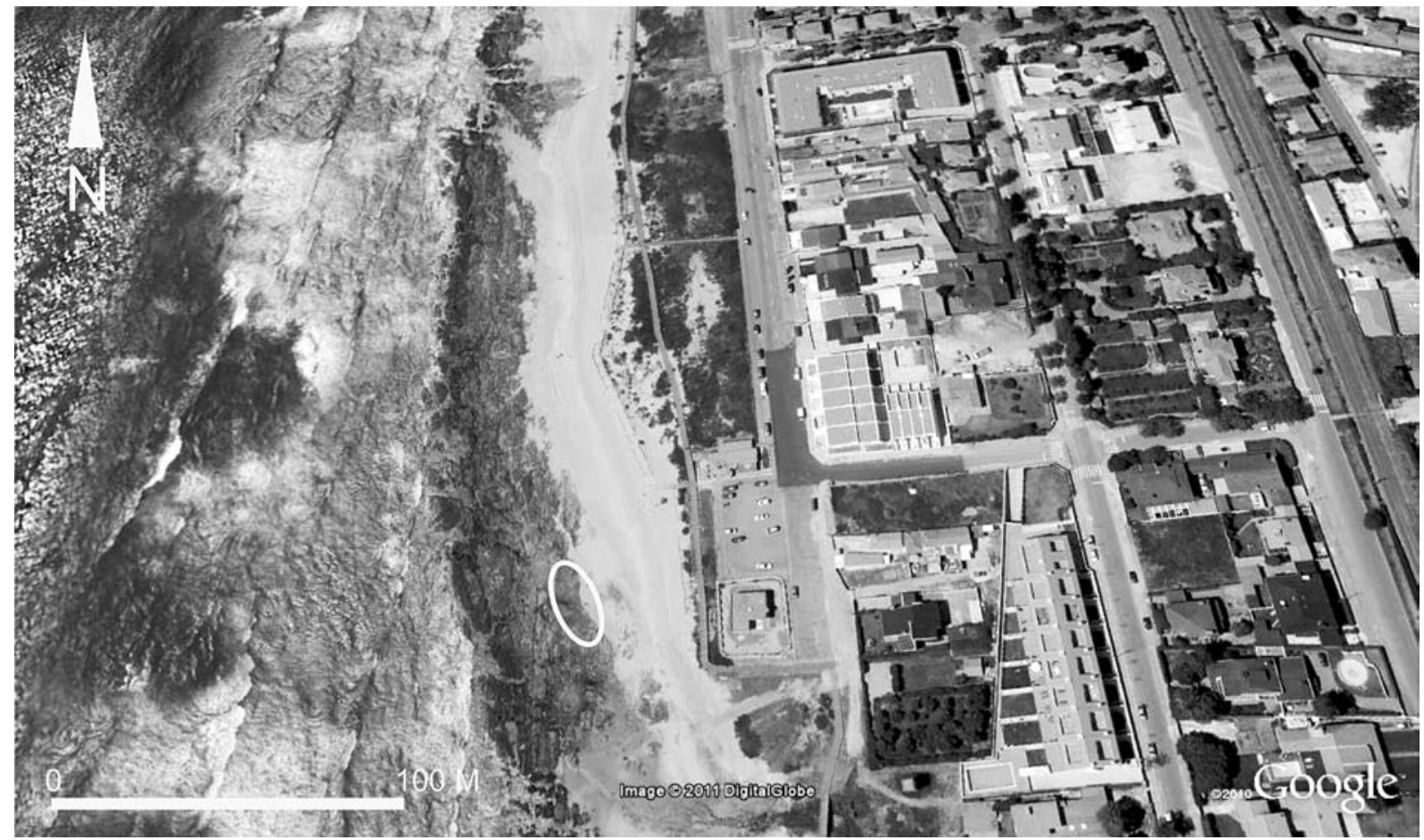

Fig. 2. Vista aérea oblíqua da estação paleolítica da Praia da Aguda (assinalada pela elipse). Imagem extraída do programa informático Google Earth, versão 6.0.3.2197. Data da imagem de satélite: 26-06-2007. Imagem modificada.

Fig. 2. Aerial oblique view of the Palaeolithic site of Praia da Aguda (marked by the ellipse). Picture taken from Google Earth, version 6.0.3.2197. Date of the satellite image: 26-06-2007. Modified image.

maior concentração de artefactos (que coincide com o local onde era visível um dos maiores afloramentos da praia fóssil) são as seguintes: $41^{\circ} 02^{\prime} 39,07^{\prime} \mathrm{N}$ $8^{\circ} 39^{\prime} 08,94^{\prime}$ W (de Greenwich). Em termos administrativos, o sítio pertence à freguesia de Arcozelo, concelho de Vila Nova de Gaia, distrito do Porto.

\subsection{Enquadramento geológico e geomorfológico}

Como acima se referiu, na área onde se concentravam os artefactos líticos foi possível observar vestígios de um depósito marinho conglomerático, composto por areia e pequenos seixos fortemente cimentados por óxido de ferro, apresentando coloração castanho-avermelhada. Este depósito assentava sobre um complexo de rochas constituído por metassedimentos, rochas granitóides, gnaisses, filões e massas aplito-pegmatíticas (TEIXEIRA et al. 1962), que integram localmente a Zona de Ossa-Morena (CHAMiné et al. 2003).

Implantado a uma cota de cerca de $1 \mathrm{~m}$ a.n.m., o depósito marinho deverá datar, segundo ARAÚJO (2008; ARAÚJO et al. 2003), da última interglaciação (Eemiano) (Figs. 3 e 4). Ainda de acordo com a mesma investigadora, a sua reduzida altitude na área da praia da Aguda poderá documentar eventuais fenó- menos recentes de subsidência. $\mathrm{Na}$ área de Lavadores (a cerca de $10 \mathrm{~km}$ a norte da Aguda), depósitos semelhantes do ponto de vista sedimentar, pontualmente conservados nos interstícios de uma plataforma de erosão marinha sobrelevada, encontram-se a aproximadamente $7 \mathrm{~m}$ a.n.m, sugerindo, por seu turno, soerguimento tectónico (ARAÚJO 2008).

A referida subsidência sugerida para a zona da praia da Aguda seria assim responsável pela sobreposição de depósitos de diferentes idades, nomeadamente depósitos marinhos, contrariando a tendência regional para o desenvolvimento de um litoral em escadaria. Efectivamente, o depósito eemiano da praia da Aguda encontra-se recoberto por um depósito lacustre, datado de $8.67 \pm 0.78 \mathrm{ka}$ (TL), e em alguns locais por coluviões, aos quais se sobrepõe um outro depósito marinho ferruginoso, presumivelmente de idade flandriana (idem).

Excluindo a hipótese de movimentações tectónicas, a baixa altitude do depósito marinho da Aguda poder-se-ia explicar pelo facto dele assentar sobre uma superfíce anteriormente rebaixada pelo encaixe de uma pequena ribeira que desagua no mar, entre a praia da Aguda e a praia da Granja (Fig. 3) (ARAÚJO 2008). A ser assim, ter-se-ia de aceitar que o embutimento desta ribeira - bem como o de muitas outras existentes no litoral de Vila Nova de Gaia, 


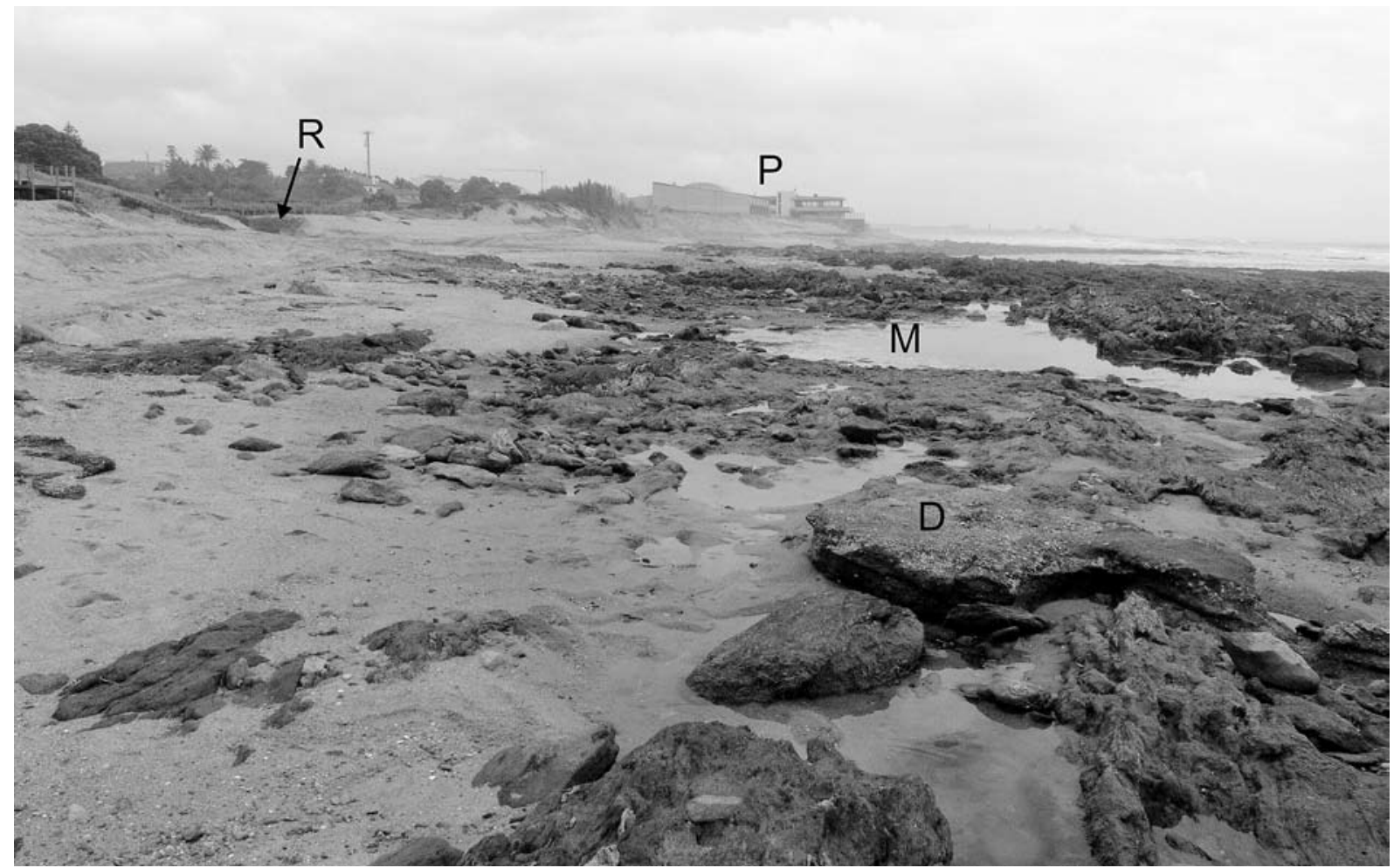

Fig. 3. Estação paleolítica da Praia da Aguda. Vista de Norte. D - Pequeno afloramento do depósito marinho do Eemiano. M - Área rebaixada com maior concentração de materiais líticos talhados; R - Ribeira; P - Piscinas da Granja.

Fig. 3. The Palaeolithic site of Praia da Aguda. View from the north. D - Small outcrop of the Eemian marine deposit. M - Recessed area with the highest concentration of lithic material. $\mathrm{R}$ - Stream, P - Granja swimming pool.

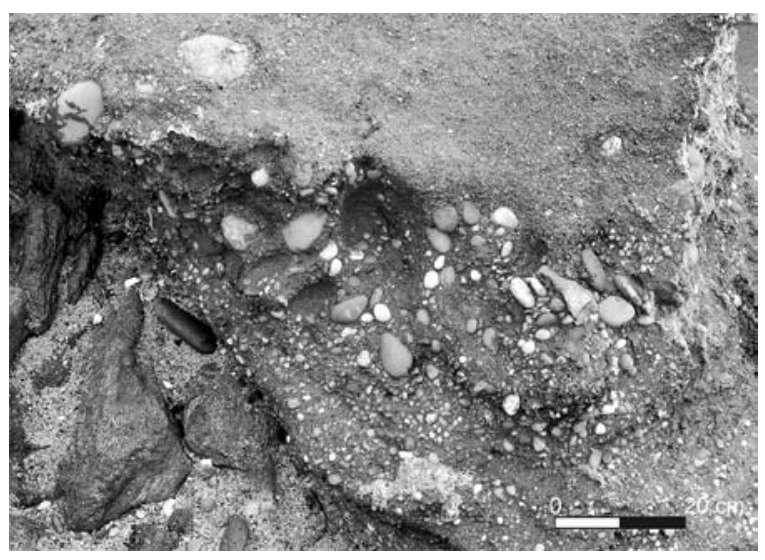

Fig. 4. Pormenor do depósito marinho conglomerático do Eemiano.

Fig. 4. Detail of the Eemian marine conglomeratic deposit.

responsáveis pela drenagem dos terrenos a oeste do "relevo marginal" (ARAÚJO 1991) - teria uma idade plistocénica, necessariamente anterior à última interglaciação.

Aquando das primeiras visitas à estação arqueológica, partiu-se do princípio que os materais talhados se encontravam directamente associados ao depósito do Eemiano, muito embora nunca tivessem sido de- tectados artefactos no seio do conglomerado ferruginoso que constitui a praia fóssil. Mais recentemente, confirmou-se que a posição de tais materiais de facto não se relaciona com aquele conglomerado, mas sim com um outro depósito de natureza areno-siltosa, de cor amarelada, muito pouco concrecionado, onde ocorrem seixos rolados de maiores dimensões, e que está presente no mesmo local (Fig. 5). À semelhança

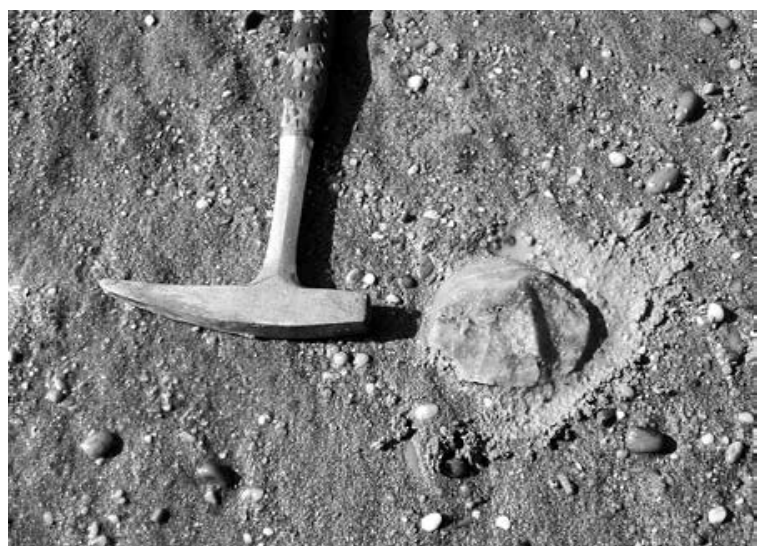

Fig. 5. Depósito areno-siltoso que contém os materiais líticos talhados.

Fig. 5. Silty-sandy deposit containing the lithic material. 
do conglomerado ferruginoso, este depósito preenche também áreas mais baixas do substrato (Fig. 3).

Como se pode depreender, as diferenças de natureza sedimentar entre estes depósitos, juntamente com a inexistência de relações estratigráficas entre si, não permitem compreender, para já, se se trata da mesma formação (correspondendo as referidas diferenças a simples variações laterais do mesmo depósito) ou de formações distintas (quer em termos de sedimentogénese, quer em termos cronológicos). Torna-se por isso fundamental desenvolver o trabalho de campo e o trabalho analítico, num quadro de colaboração com investigadores de outros domínios, por forma a poder determinar-se com mais rigor a posição estratigráfica dos artefactos líticos.

\subsection{O material lítico talhado}

As diversas visitas à estação da praia da Aguda permitiram, até ao momento, recolher 156 artefactos líticos talhados, encontrando-se a sua esmagadora maioria in situ. Efectivamente, a maior parte dos materiais foi retirada do depósito areno-siltoso a que acima se aludiu (posicionam-se praticamente no contacto com o substrato metamórfico) e não apresenta sinais de boleamento.

Muito embora este conjunto artefactual careça ainda de um estudo detalhado (e sobretudo de um aumento da amostragem), é possível desde já avançar algumas impressões de natureza tecno-tipológica. Assim, as diversas categorias identificadas foram as seguintes:

\begin{tabular}{|l|c|}
\hline Núcleos & 53 \\
\hline Lascas & 49 \\
\hline Seixos talhados & 12 \\
\hline Fragmentos (de talhe ou com talhe) & 26 \\
\hline Percutores (seixos com marcas de percussão) & 4 \\
\hline Seixos talhados tipo "peso-de-rede" & 2 \\
\hline Utensílios & 10 \\
\hline
\end{tabular}

Para além de 28 peças talhadas a partir de seixos de quartzito, todas as restantes (128) foram produzidas a partir de quartzo leitoso. Este mineral ocorre localmente em estreitos filões encaixados nos xistos porfiroblásticos granatíferos, aflorantes numa vasta área da praia da Aguda (TEIXEIRA et al. 1962). Ocorre também sob a forma de grandes seixos rolados, alguns dos quais com dimensão decimétrica a métrica (Fig. 6).

A alteração das rochas encaixantes e as abundantes fracturas dos filões terão facilitado o seu desmantelamento, quer através de processos naturais, quer devido a acção antrópica. A utilização no talhe de placas de quartzo não boleadas, que conservam ainda finas películas de micaxistos com granadas, sugere a exploração dos filões por parte do Homem paleolítico (Fig. 7).

Quanto aos núcleos, é de referir desde logo a sua grande dimensão, havendo peças que atingem os $50 \mathrm{~cm}$ (dimensão máxima) (Figs. 6, 8 e 9). No que diz respeito à exploração, os blocos ou seixos rolados que lhes servem de suporte terão sido, em certos casos, projectados violentamente sobre percutor dormente, fracturando-se em inúmeros fragmentos com

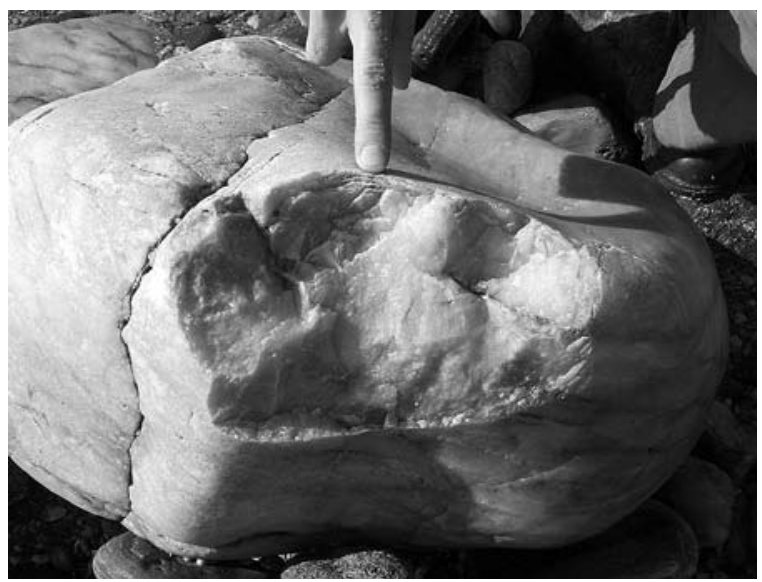

Fig. 6. Núcleo sobre seixo rolado de quartzo de grandes dimensões.

Fig. 6. Large core on quartz pebble.

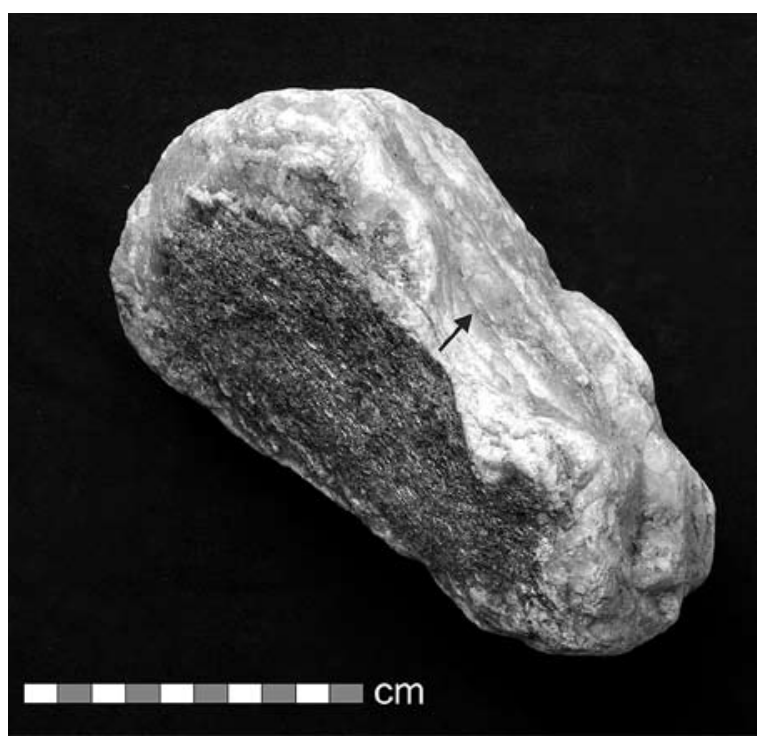

Fig. 7. Núcleo (a seta indica a direcção de uma das extrações). Observe-se a presença de uma superfície micácea com granadas, testemunhando a utilização do quartzo filoniano local.

Fig. 7. Core (the arrow indicates the direction of one of the extractions). Note the presence of a micaceous surface with grenades, confirming the use of local filonian quartz. 


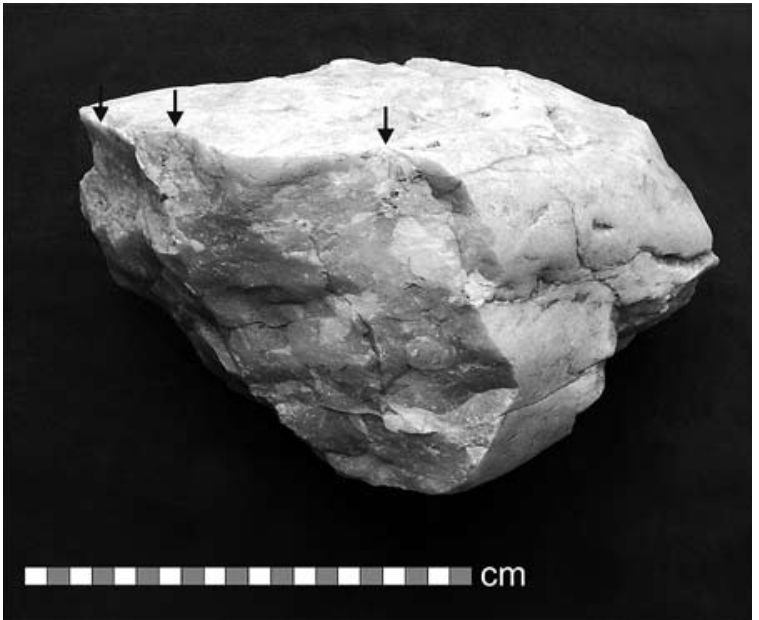

Fig. 8. Núcleo sobre seixo de quartzo de grandes dimensões. As setas indicam a direcção de algumas das extrações.

Fig. 8. Large core on quartz pebble. The arrows indicate the direction of some of the extractions.

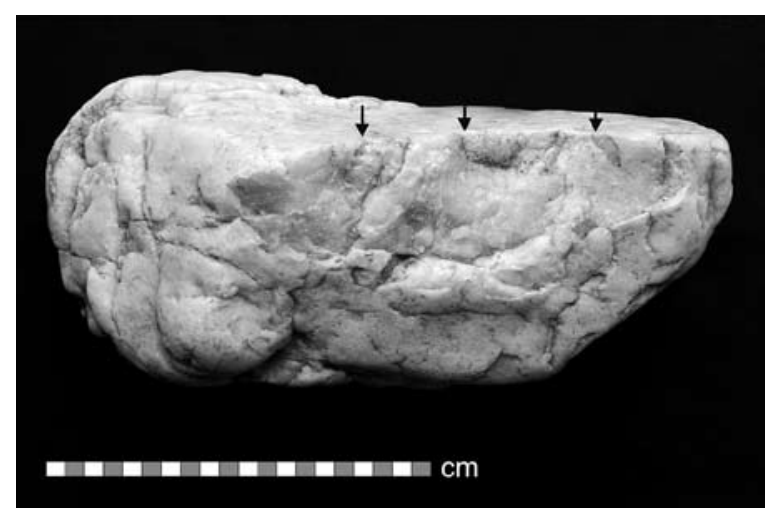

Fig. 9. Núcleo sobre seixo de quartzo de grandes dimensões. As setas indicam a direcção das extrações.

Fig. 9. Large core on quartz pebble. The arrows indicate the direction of some of the extractions.

dimensão e morfologia muito variável (contabilizados na categoria "fragmentos de talhe" ou "fragmentos com talhe"). Alguns destes fragmentos, por seu turno, foram explorados seguindo estratégias diversificadas: desde estratégias que se podem considerar expeditas (núcleos tendencialmente globulosos ou poliédricos) (Fig. 10) a outras que implicam uma preparação mais complexa do bloco a debitar (núcleos centrípetos, “discóides" e levallois) (Figs. 11, 12 e 13).

Nos casos em que a projecção dos blocos originou verdadeiras lascas - isto é, porções de quartzo em que é possível identificar uma face de estalamento, por vezes com um bolbo (situação muito pouco frequente neste tipo de matéria-prima), e uma face dorsal, por vezes cortical - observou-se debitagem sobre face plana, que pode ser tendencialmente cen-

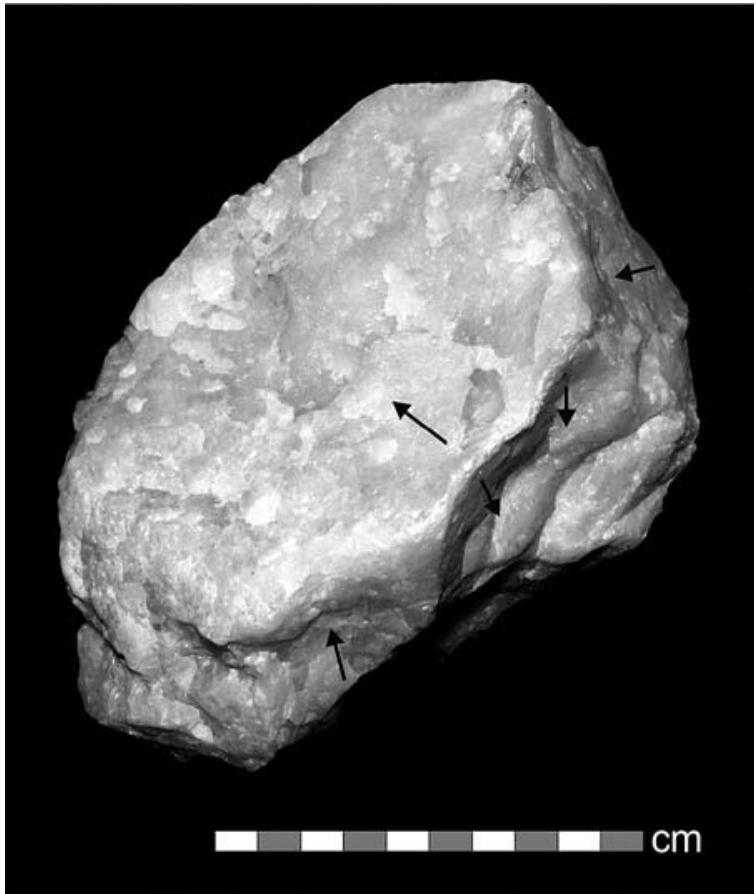

Fig. 10. Núcleo poliédrico sobre seixo de quartzo. As setas indicam a direcção de algumas das extrações.

Fig. 10. Polyhedral core on quartz pebble. The arrows indicate the direction of some of the extractions.

trípeta (Fig. 14) ou visar a extração de uma única lasca (método de debitagem Kombewa) (Fig. 15).

Outros casos há em que os seixos de quartzo, em função das suas grandes dimensões, terão sido debitados através da projecção de um percutor sobre os respectivos planos de percussão (Fig. 6). Tanto esta estratégia de fragmentação como a anteriormente referida (projecção do bloco/ núcleo sobre um percutor dormente) originaram nos núcleos, nas lascas e nos fragmentos de talhe pontos de impacto bastante bem marcados.

De um modo geral, os núcleos apresentam um número reduzido de extrações, sugerindo que apenas foram debitados para avaliação da qualidade da matéria-prima.

Relativamente às lascas, importa desde logo sublinhar a dificuldade no seu reconhecimento. Como se referiu, o tipo de quartzo utilizado nesta indústria, afectado por intensa deformação resultante de metamorfismo e com textura heterogénea, apresenta um padrão de fragmentação muito irregular, muitas vezes condicionado por superfícies de fractura preexistentes. Por esta razão, as faces de estalamento não são verdadeiramente conchoidais, os bolbos são raros e os cones de percussão estão quase sempre ausentes, pelo que, praticamente, não se dispõe de elementos de diagnóstico para as lascas (Fig. 16).

Do ponto de vista da sua debitagem, as lascas de 


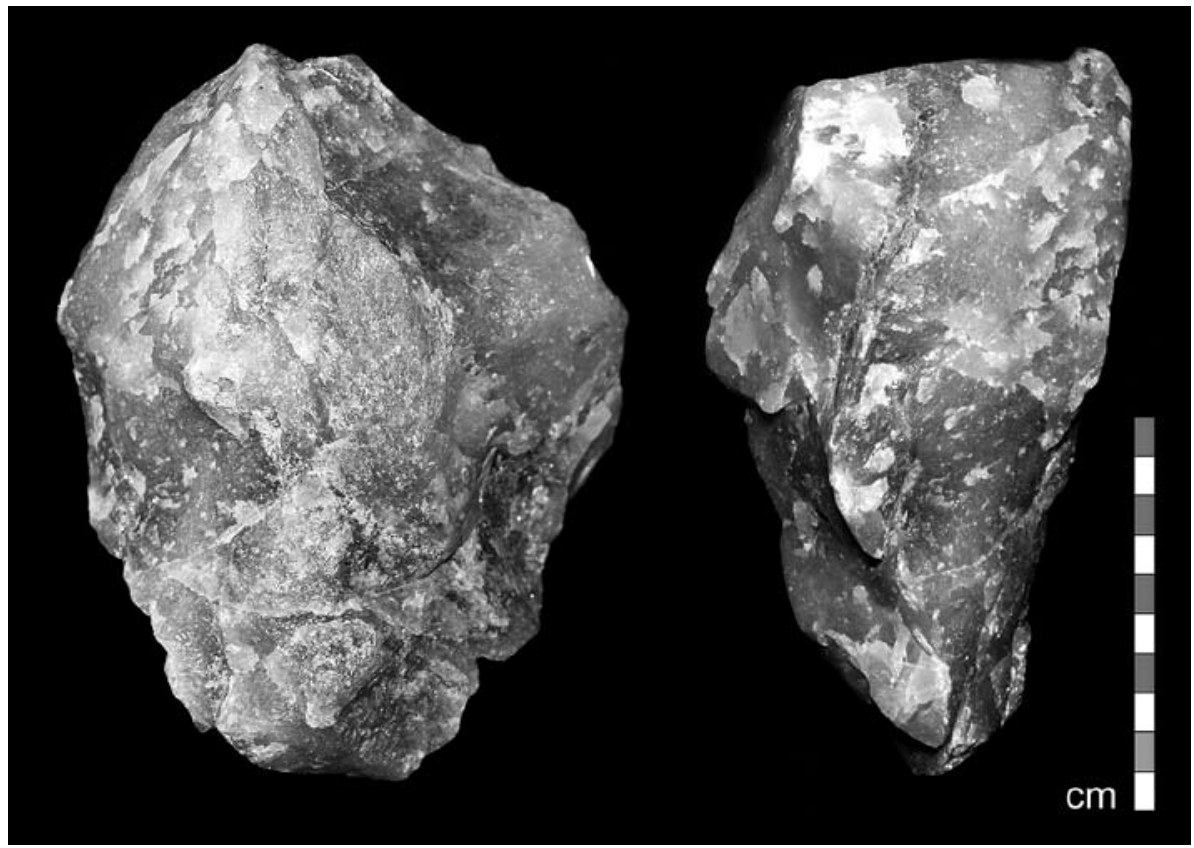

Fig. 11. Núcleo com extrações centrípetas sobre fragmento de quartzo.

Fig. 11. Core on quartz fragment with centripetal extractions.

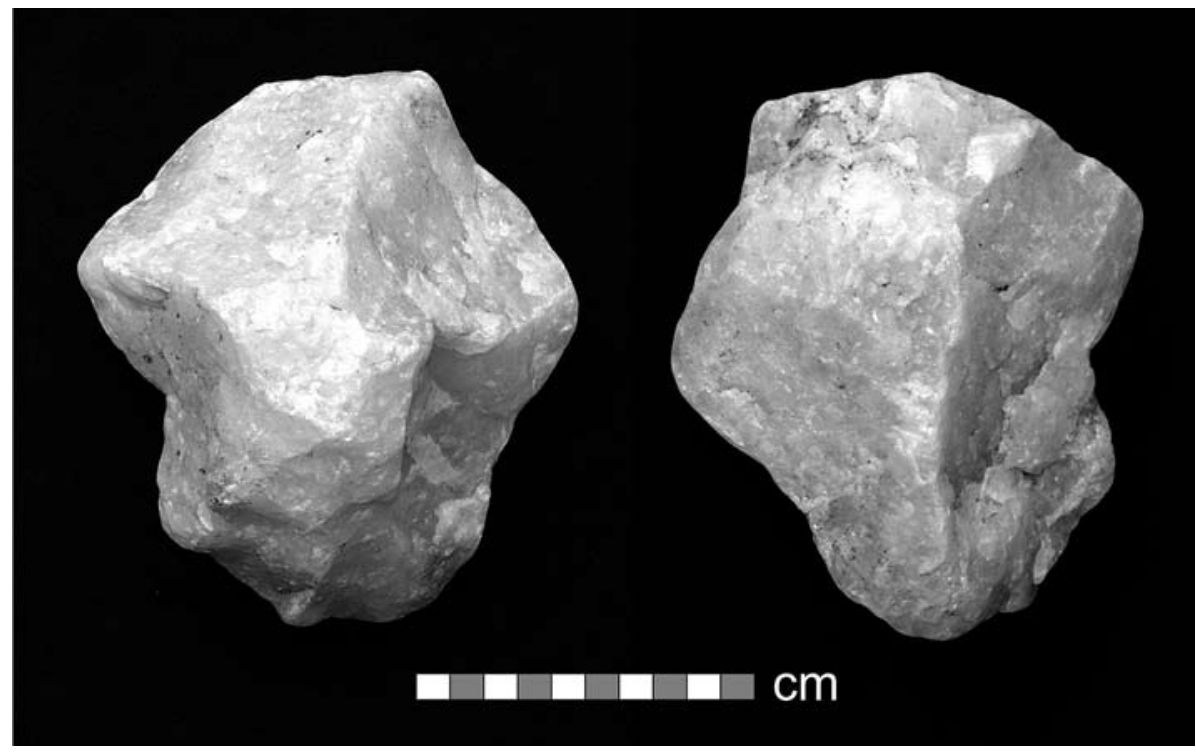

Fig. 12. Núcleo com extrações centrípetas bifaciais sobre fragmento de quartzo.

Fig. 12. Core on quartz fragment with bifacial centripetal extractions. 


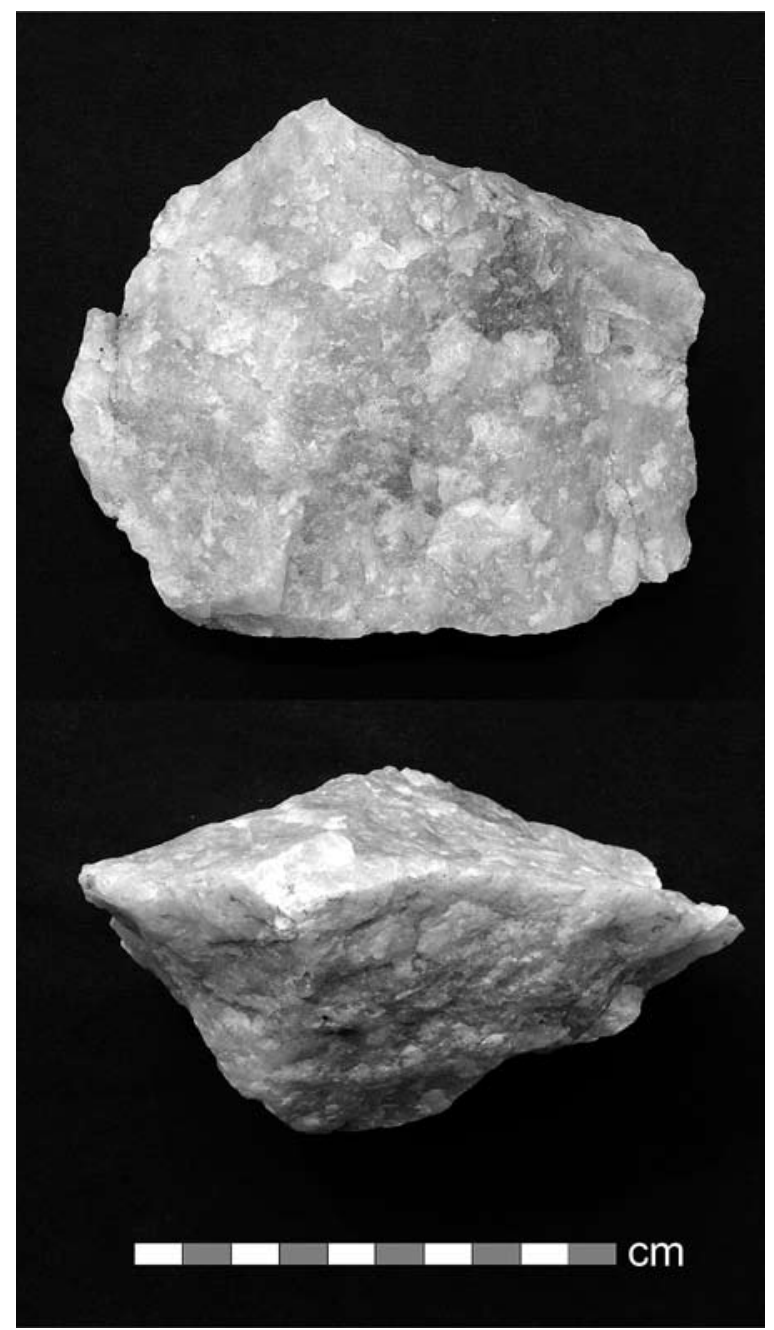

Fig. 13. Núcleo levallois recorrente centrípeto.

Fig. 13. Centripetal recurrent Levallois core.

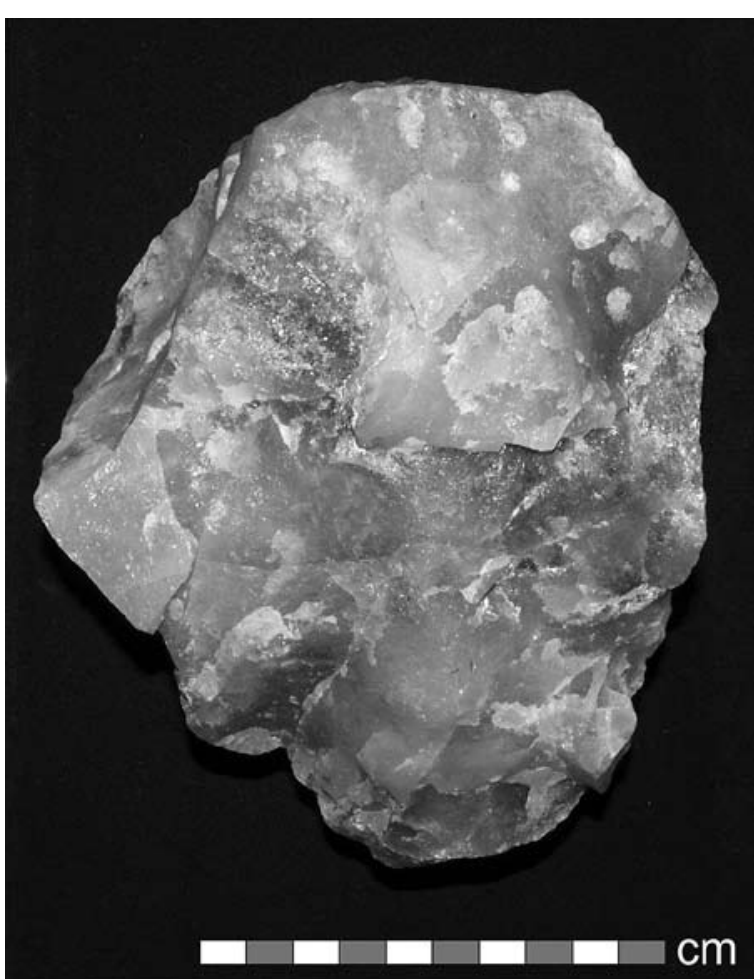

Fig. 14. Núcleo sobre lasca com extrações centrípetas sobre face plana.

Fig. 14. Flake-core with centripetal extractions on the ventral surface.

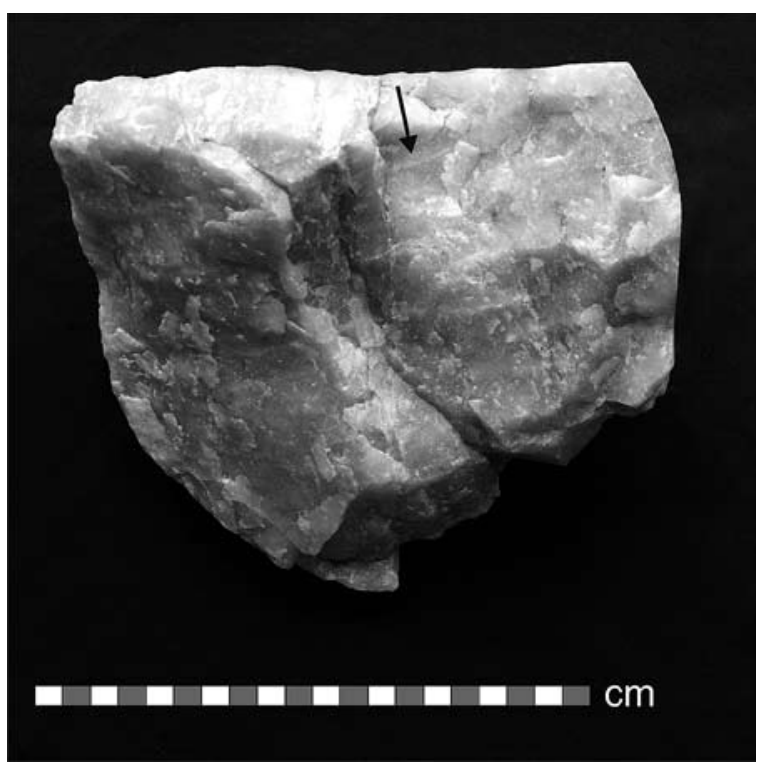

Fig. 15. Núcleo Kombewa (o negativo abrange a área correspondente ao bolbo da lasca-núcleo).

Fig. 15. Kombewa core (the negative covers the area corresponding to the bulb of the flake-core). 


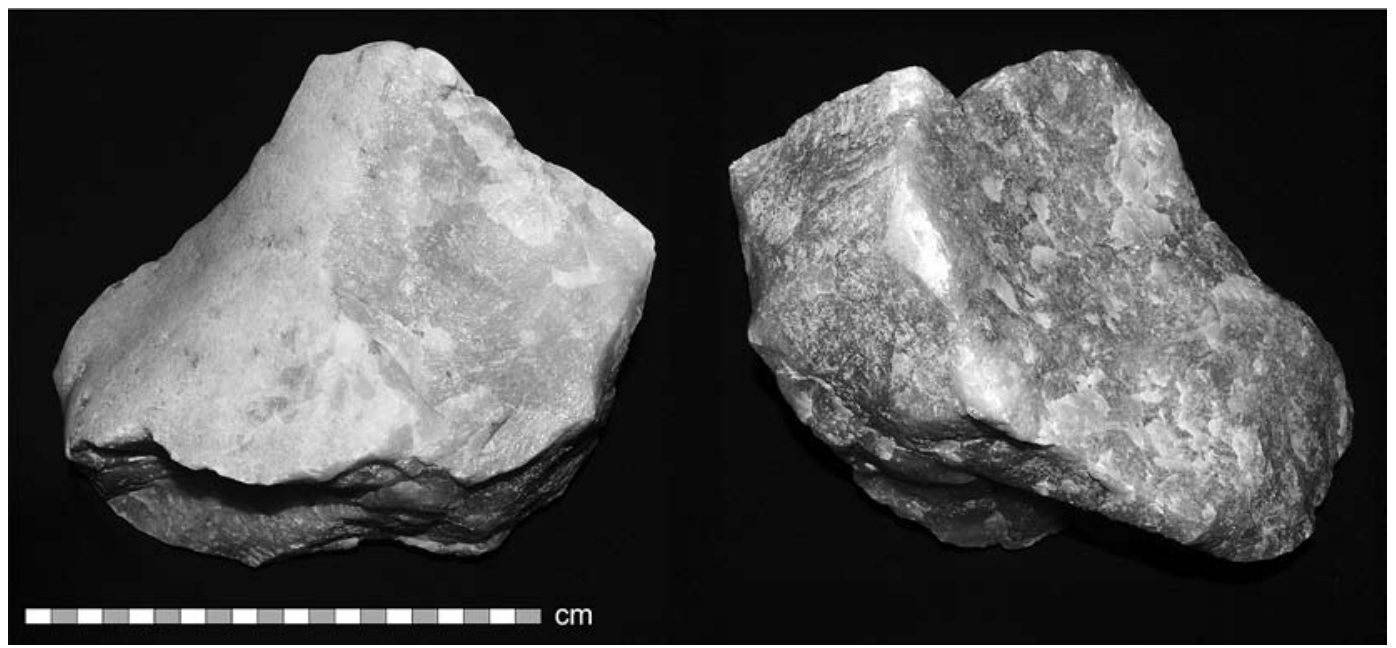

Fig. 16. Lasca de quartzo. Observe-se a morfologia da face de estalamento (à direita).

Fig. 16. Quartz flake. Note the morphology of the ventral surface (on the right).

maiores dimensões (que podem alcançar os $30 \mathrm{~cm}$ de comprimento máximo) apresentam toda uma série de acidentes de talhe - buris de Siret, ressaltos, esmagamento dos talões, etc. - que configuram situações de percussão violenta, o que, aliás, coincide com o que se referiu a propósito dos núcleos. Algumas delas evidenciam levantamentos pontuais posteriores à debitagem, que poderão corresponder a "testes de qualidade" da matéria-prima para a sua eventual utilização como núcleos ou mesmo como utensílios.

Entre os seixos talhados, quase todos em quartzito, incluiram-se, provisoriamente, peças que poderão corresponder a choppers e outras que poderão ser classificadas como núcleos. Em todo o caso, o que importa para já referir a propósito destes artefactos é a presença de dois conjuntos com graus de boleamento claramente distintos: um com peças muito roladas e outro com peças sem rolamento (ou com peças com rolamento muito ténue). Uma vez que foram detectados in situ alguns artefactos desta categoria (Fig. 5), considera-se que também os seixos talhados farão parte integrante desta indústria. Todavia, a ocorrência de dois objectos semelhantes a "pesos-de-rede" com elevado grau de rolamento, e de um percutor sem rolamento, aparentemente com vestígios de polimento, poderá indiciar a existência, neste sector do litoral, de outros conjuntos artefactuais mais recentes do que aquele que ocorre no depósito areno-siltoso. Tal situação recomenda, portanto, que em estudos futuros apenas se considerem como fazendo parte da indústria em análise materiais líticos sobre seixo de quartzito que apresentem características tecno-tipo- lógicas particulares ou, então, que surjam em clara associação ao referido depósito geológico.

Quanto aos utensílios, eles distribuem-se pelos seguintes tipos:

\begin{tabular}{|l|c|}
\hline Biface parcial sobre placa de quartzo de filão & 1 \\
\hline Biface parcial sobre lasca (ou placa) de quartzo de filão & 1 \\
\hline $\begin{array}{l}\text { Esboço de machado de mão sobre lasca de quartzo de } \\
\text { filão }\end{array}$ & 1 \\
\hline Machado de mão sobre lasca de quartzo & 1 \\
\hline Raspadores sobre lasca de quartzo & 2 \\
\hline Esboço de raspador sobre face plana em quartzo & 1 \\
\hline $\begin{array}{l}\text { Utensílio apontado com extremidade distal de secção } \\
\text { triangular em quartzo de filão }\end{array}$ & 1 \\
\hline Raspador inverso sobre calote de seixo de quartzo & 1 \\
\hline $\begin{array}{l}\text { Lasca com retoque convergente que origina uma pequena } \\
\text { extremidade distal, em quartzo de filão }\end{array}$ & 1 \\
\hline
\end{tabular}

Em relação aos bifaces, é de referir o seu aspecto expedito; ou seja, parece ter havido selecção de suportes aplanados, naturalmente propícios à produção deste tipo de artefacto, com uma clara "economia de gestos" (CUNHA-RIBEIRO 1992-1993, 1999) (Figs. 17 e 18).

Esta mesma lógica expedita é extensível a um dos machados de mão (Fig. 19). Já o outro apresenta uma certa sofisticação, patente, desde logo, na sua silhueta (em U) e na sua simetria. Trata-se de uma peça bem equilibrada, com gume rectilíneo, perfeitamente perpendicular ao respectivo eixo de simetria longitudinal. Embora pareça tratar-se de um machado de mão de tipo 0 [ou "proto-hachereau", segundo J. Tixier (1956) $]^{4}$, este artefacto foi alvo de diversos

4 Veja-se também J.P. Cunha-Ribeiro (1999) e S. Monteiro-Rodrigues (1996). 


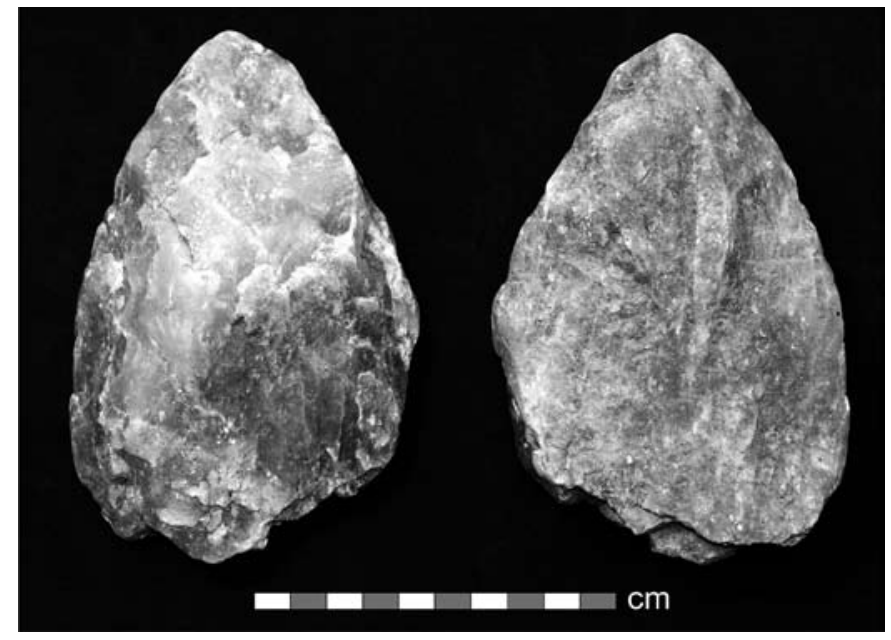

Fig. 17. Biface parcial sobre placa de quartzo de filão (extremidade proximal fracturada).

Fig. 17. Partial handaxe on filonian quartz plate (proximal end broken)

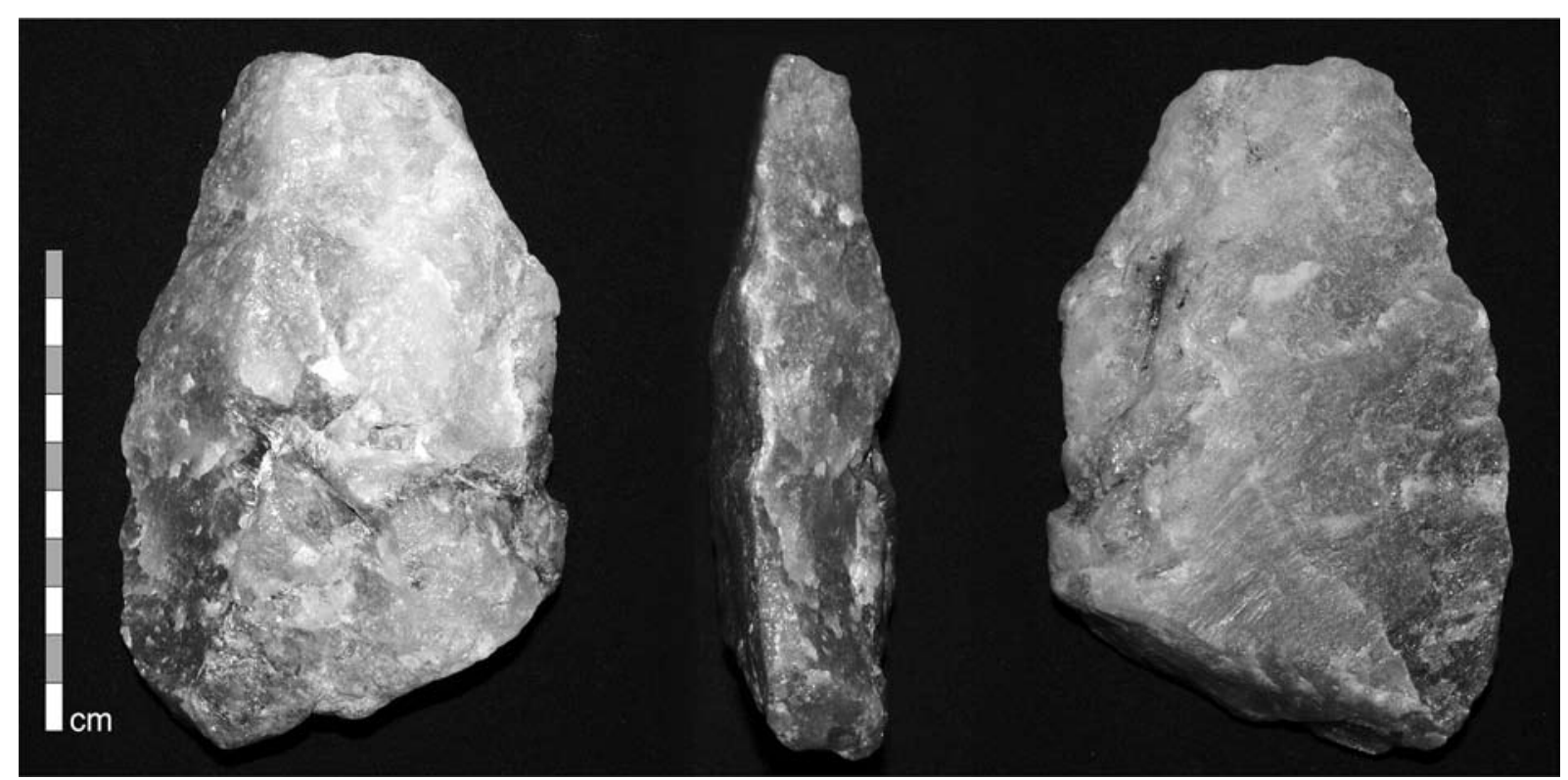

Fig. 18. Biface parcial sobre lasca (ou placa?) de quartzo de filão (extremidade distal fracturada).

Fig. 18. Partial handaxe on filonian quartz flake (or plate?) (proximal end broken).

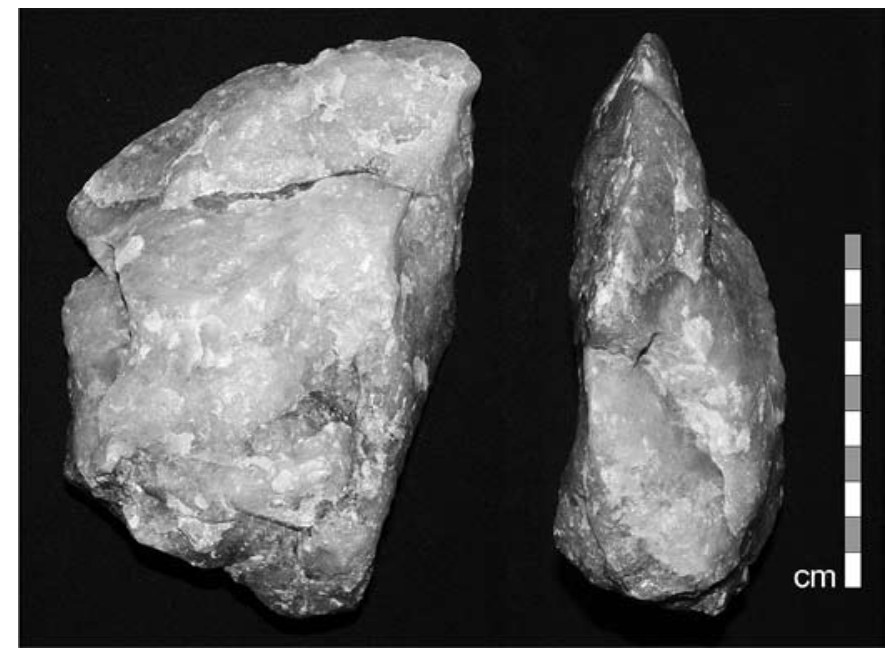

Fig. 19. Esboço de machado de mão sobre lasca de quartzo de filão.

Fig. 19. Cleaver on filonian quartz flake. 
levantamentos (que terão suprimido parte do córtex da lasca-suporte), não só destinados à regularização da zona activa, como também das regiões supostamente destinadas à preensão (Fig. 20).

Relativamente aos dois raspadores indicados no quadro, é de salientar a sua grande dimensão. Num deles, o retoque (retoque directo) afecta apenas uma pequena parcela da aresta da lasca, sugerindo tratar-se de uma peça inacabada. Em alternativa, poder-se-á supor que a reduzida extensão do retoque se relaciona com o carácter expedito patente nesta indústria.

Quanto aos restantes utensílios, não se dispõe para já de observações dignas de registo.

\section{DisCuSSÃo}

As condições de jazida dos materiais líticos recolhidos na estação paleolítica da praia da Aguda permitem avançar algumas hipóteses relativamente à formação do sítio arqueológico e à sua cronologia relativa.

Assumindo que o depósito onde o material ocorre corresponde simplesmente a uma variação lateral da praia atribuída ao Eemiano, estar-se-ía, então, perante uma indústria lítica produzida num momento grosso modo coincidente com o início daquela fase transgressiva. Nessa fase deveria existir na área da actual praia da Aguda uma superfície rochosa desprovida de cobertura sedimentar (ou pontualmente coberta por sedimentos de origem continental ou de origem marinha), que permitia aceder aos filões de quartzo encaixados no substrato proterozóico.

A ocorrência no local de seixos rolados de quartzo de grandes dimensões (em alguns casos explorados como núcleos) permite levantar a hipótese de nesta fase haver já um certo avanço do mar no sentido do continente, que seria responsável pela sua deposição. Tendo em conta o seu peso elevado, essa deposição poderia relacionar-se com tempestades em que ondas com elevado potencial energético alcançariam episodicamente faixas mais interiores da plaforma litoral, cobrindo-as também com sedimentos mais finos. De facto, tal hipótese é perfeitamente compatível com o que se observa do ponto de vista arqueológico: a quase total ausência de peças boleadas numa colecção que se apresenta técnica e tipologicamente homogénea, que surge espacialmente concentrada e que assenta praticamente no substrato sugere a ocorrência de um evento "único" responsável pelo seu soterramento. Em todo o caso, não se exclui, naturalmente, a possibilidade dos grandes seixos de quartzo já existirem na plataforma rochosa, relacionando-se, como se referiu, com coberturas sedimentares preexistentes.

Se, por outro lado, se partir do princípio que o depósito onde surge o material lítico corresponde a uma outra formação distinta do depósito marinho atribuído à última interglaciação, poder-se-á aceitar a possibilidade de se tratar de um depósito mais re-

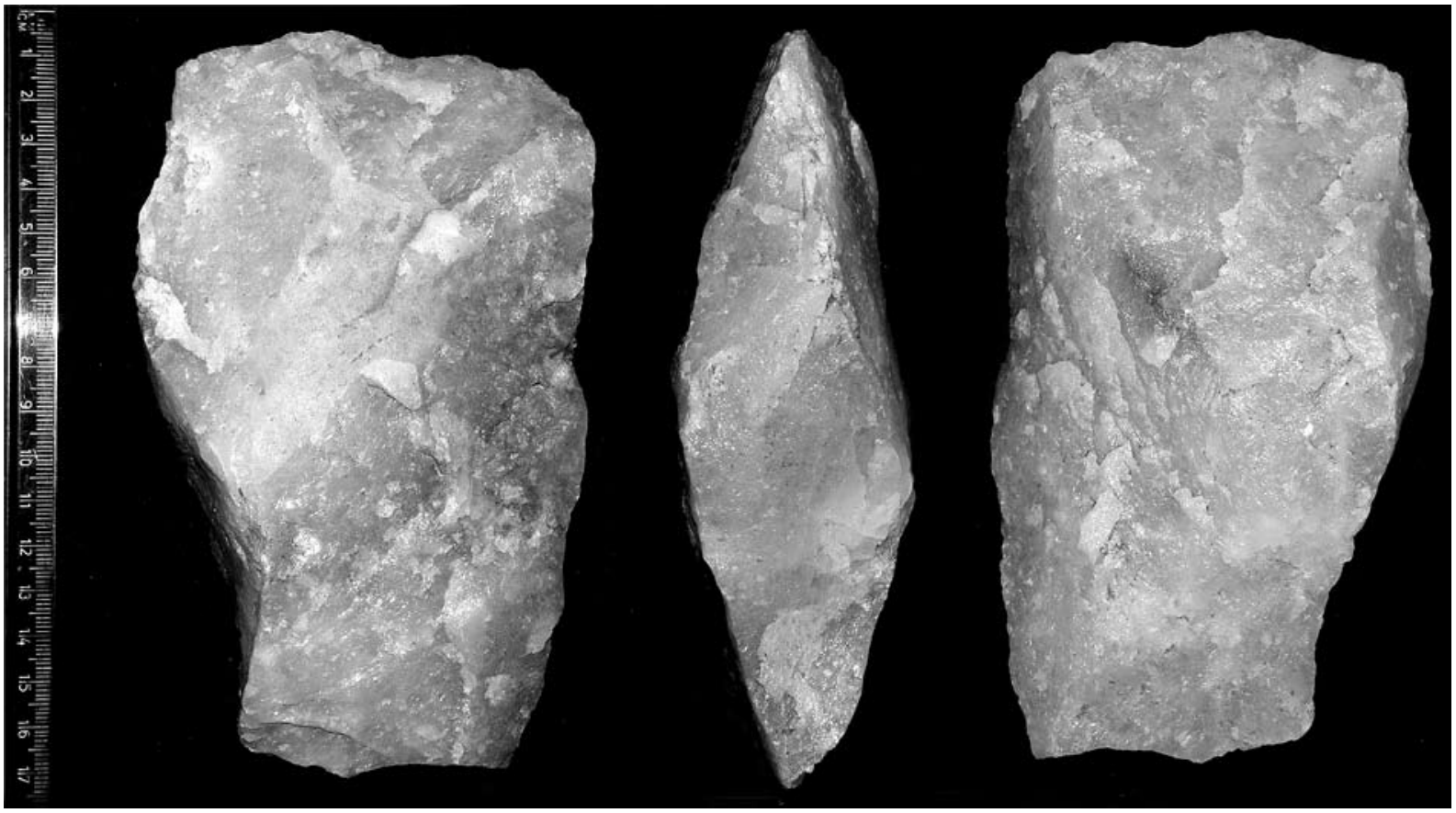

Fig. 20. Machado de mão sobre lasca de quartzo.

Fig. 20. Cleaver on filonian quartz flake. 
cente, acumulado sobre a plataforma rochosa anteriormente coberta pelo depósito do Eemiano. Ou seja, após o início da regressão marinha atribuída à última glaciação, o depósito marinho eemiano poderia ter ficado sujeito a processos erosivos responsáveis pelo seu desmantelamento. Seria então possível, em certos locais, explorar os filões de quartzo do substrato metamórfico (agora aflorantes) e mesmo o material detrítico originalmente associado à praia elevada (seixos rolados).

Neste contexto de remobilização dos sedimentos de origem marinha (aos quais se juntariam algumas contribuições continentais, como o silte, entre outras) poder-se-iam ter formado depósitos coluvionares (através de mecanismos de solifluxão, por exemplo), que cobririam superfícies expostas da plataforma de erosão marinha (e depósitos marinhos "residuais" que sobre ela tivessem ficado conservados), e que enterrariam os materiais líticos talhados. O estado físico "fresco" destes materiais e o facto de se concentrarem numa área relativamente restrita levam a admitir que os movimentos da massa coluvionar seriam de curta extensão.

Uma outra hipótese que se pode aventar - em função da ocorrência de silte/argila no depósito que contém o material lítico - seria a da sua origem lagunar. Numa fase de regressão marinha, que teria possibilitado ao Homem paleolítico o acesso aos filões de quartzo e a seixos rolados, ter-se-ia formado uma lagoa litoral (tal como sucedeu em diversas etapas da evolução da costa (p.e. ARAÚJO 2008)) em cujos depósitos ficariam conservados os artefactos talhados. Posteriormente, numa fase transgressiva, esses depósitos seriam cobertos por sedimentos marinhos grosseiros, essencialmente cascalhentos e ricos em seixos.

Tendo em conta que o depósito marinho fóssil da praia da Aguda poderá ter uma idade eemiana, e aceitando a possibilidade de ele se sobrepor estratigraficamente ao depósito que contém a indústria lítica (facto que não pôde ainda ser confirmado localmente), então este último (depósito lagunar) ter-se-ia formado, provavelmente, no decurso de fases regressivas ocorridas durante aquele interglaciar (ARAÚJo, inf. pess.; ARAÚJO et al. 2010; CUFFEY \& MARSHALL 2000).

Em suma, os materiais líticos talhados da praia da Aguda poderão datar de um período que coincide genericamente com o início da última interglaciação, caso se confirme a sua associação ao depósito marinho considerado do Eemiano. Na eventualidade de se relacionarem com um depósito coluvionar, datarão da última glaciação, possivelmente da sua fase inicial. Poderão ainda datar de um intervalo temporal mais difícil de precisar (enquadrável genericamente no último interglaciar) caso se encontrem associados a um depósito lagunar. Seja como for, estas cronologias são compatíveis com as características tecno-tipológicas observadas na indústria lítica.

\section{Conclusĩo}

Este texto teve como principal objectivo a apresentação da estação paleolítica da Praia da Aguda. Para além disso, todos os aspectos abordados deverão ser entendidos como preliminares.

Efectivamente, a compreensão dos processos subjacentes à formação do sítio arqueológico e sua cronologia - ou seja, as questões de natureza geoarqueológica - dependem de investigação futura, que deverá ser desenvolvida, preferencialmente, no âmbito de estudos interdisciplinares.

A própria caracterização da indústria identificada passa também pela constituição de uma amostragem artefactual bastante mais expressiva e pela realização de estudos técnicos e tipológicos mais detalhados.

No curto prazo, é fundamental proceder a diversos registos de campo e à recolha intensiva de material arqueológico, uma vez que acção erosiva do mar (incrementada pela construção do paredão da Aguda) está a pôr em risco a conservação não só da estação arqueológica, como também dos depósitos plistocénicos da envolvente, fundamentais para o seu entendimento.

\section{BIBLIOGRAFIA}

AraúJO, M.A. 1991. Evolução Geomorfológica da Plataforma Litoral da Região do Porto. Porto: Faculdade de Letras da Universidade do Porto. Dissertação de Doutoramento (policopiado).

ARAÚJO, M.A. 1995. Os fácies dos depósitos würmianos e holocénicos e as variações climáticas correlativas na plataforma litoral da região do Porto. Actas do VI Colóquio Ibérico de Geografia. Porto: Publicações da Universidade do Porto: 783-793.

ARAúJo, M.A. 2000. Depósitos continentais e marinhos na plataforma litoral da região do Porto: importância da tectónica na sua organização espacial. Ciências da Terra 14: 111-122.

AraúJo, M.A. 2004. O final do Cenozóico na plataforma litoral da região do Porto. In M.A. Araújo \& A. Gomes (Eds.) Geomorfologia do NW da Península Ibérica. Porto: Faculdade de Letras da Universidade do Porto e GEDES: 117-137.

AraúJo, M.A. 2008. Depósitos do Pleistocénico Superior e do Holocénico na plataforma litoral da região do Porto: a morfologia das plataformas de erosão marinha e a tectónica recente. Estudos do Quaternário 5:17-30.

AraúJo, M.A.; Gomes, A.; Chaminé, H.I.; FonseCA, P.E.; GAmA Pereira, L.C. \& Pinto De Jesus, A. 2003. Geomorfologia e geologia regional do sector de Porto-Espinho (W de Portugal): implicações morfoestruturais na cobertura sedimentar 
cenozóica. Cadernos do Laboratorio Xeológico de Laxe 28: 79-105.

AraúJo, M.A.; Monteiro-Rodrigues, S. \& Gomes, A. 2005. Eemien and Flandrian deposits on Porto (northern Portugal) littoral platform: the contribution of Archaeology. Sixth International Conference on Geomorphology. Geomorphology in Regions of Environmental Contrasts. Zaragoza, 7-11 Setembro. Livro de resumos: 231.

Chaminé, H.I.; Gama Pereira, L.C.; Fonseca, P.E.; Noronha, F. \& LEMOS DE SOUSA, M.J. 2003. Tectonoestratigrafia da faixa de cisalhamento de Porto - Albergaria-a-Velha - Coimbra - Tomar, entre as Zonas Centro-Ibérica e de Ossa-Morena (Maciço Ibérico, W de Portugal). Cadernos do Laboratorio Xeológico de Laxe 28: 37-78.

Cuffey, K.M. \& Marshall; Shawn J. 2000. Substantial contribution to sea-level rise during the last interglacial from the Greenland ice sheet. Nature 404: 591-594 (doi:10.1038/ 35007053).

CunHA-RiBeIRO, J.P. 1992-1993. Contribuição para o estudo do Paleolítico do vale do rio Lis no seu contexto crono-estratigráfico. Portugalia 13-14. Nova Série: 7-137.

Cunha-Ribeiro, J.P. 1999. O Acheulense no Centro de Portugal: o Vale do Lis. Contribuição para uma abordagem tecno-tipológica das suas indústrias líticas e problemática do seu contexto cronoestratigráfico. Dissertação de Doutoramento apresentada à Faculdade de Letras da Universidade de Lisboa, 3 Vols., Lisboa, policopiado.
CARTA Militar De Portugal. Folha 133 - Valadares (Vila Nova de Gaia), à escala 1:25 000, Série M888. Lisboa: Instituto Geográfico do Exército 1978.

Monteiro-Rodrigues, S. 1996. Contribuição para o estudo das Indústrias Líticas do Vale do Rio Caia (Alto Alentejo - Portugal). Porto: Faculdade de Letras do Porto. Dissertação de Mestrado (policopiada).

Monteiro-Rodrigues, S. 2000. A Pré-história Antiga da Região do Porto. Síntese Bibliográfica. Almadan 9. II Série. Almada: Centro de Arqueologia de Almada: 74-78.

Monteiro-Rodrigues, S. \& CUnHA-Ribeiro, J.P. 1991. A Estação Paleolítica do Cerro - Madalena, Vila Nova de Gaia. Revista da Faculdade de Letras da Universidade do Porto - História 8. II Série: 411-428.

Monteiro-Rodrigues, S.; SANCHES, M. DE J. 2006. Os primeiros recolectores e caçadores (Paleolítico). In C.A. Brochado de Almeida (coord.), História do Douro e do Vinho do Porto. História Antiga da Região Duriense, Vol. I. Porto: GEHVID e Edições Afrontamento: 30-77.

Teixeira, C.; Perdigão, J. \& TORRe de Assunção, C. 1962. Carta Geológica de Portugal na escala 1/50000. Notícia explicativa da folha 13-A - Espinho. Lisboa: Serviços Geológicos de Portugal.

TIXIER, J. 1956. Le hachereau dans l'Acheuléen Nord-Africain. Notes typologiques. Congrès Préhistorique de France, XVe Session, Poitiers-Angouléme: 914-923.

Weber, M. 2005. Aguda, para além das marés. Fauna, flora e pescas no mar da Aguda. Porto: Afrontamento. 